\title{
Estudo ergonômico aplicado a um posto de trabalho: cobradores de ônibus de estações-tubo de Curitiba
}

\section{Ergonomic study applied to a desk job: collectors bus station-tube Curitiba}

\author{
CARPES, Alexandre Jungles I Universidade Federal do Paraná - UFPR \\ alexandremcarpes@ig.com.br \\ TEZOLIN, Adriely Frutuoso I Universidade Federal do Paraná - UFPR \\ adriely_katze@hotmail.com \\ NEOTTI, Guilherme I Universidade Federal do Paraná - UFPR \\ guilherme_neotti@hotmail.com
}

BOSCHETE, Lucas Fernandes I Universidade Federal do Paraná - UFPR lucas_fernandesb@hotmail.com

\section{Resumo}

Esse artigo realiza uma breve apreciação ergonômica da estação-tubo do transporte público de Curitiba. O objetivo da pesquisa foi identificar as atividades realizadas no local e diagnosticar os problemas existentes.

Palavras Chave: Posto de trabalho. Apreciação ergonômica. Ponto de ônibus.

\section{Abstract}

This article provides a brief assessment of ergonomic tube station of public transport in Curitiba. The objective of the research was to identify the activities performed at the site and diagnose problems.

Keywords: Job. Ergonomic Assessment. Bus stop. 


\section{INTRODUC̣ÃO}

O presente artigo busca detalhar à luz dos conceitos ergonômicos, o ambiente de trabalho das estações-tubo do transporte de Curitiba.

O local escolhido para estudo é uma das estações existentes na região do Largo Bittencourt, mais conhecido como Círculo Militar. Seu detalhamento espacial será feito em várias etapas a seguir, buscou-se o detalhamento do sistema homem-máquina, o fluxograma de funcionamento desse sistema e o detalhamento dos problemas ergonômicos encontrados por meio do sistema GUT. Foram tiradas fotos do local, facilitando assim a percepção das falhas de projeto que podem vir a prejudicar os funcionários, bem como os usuários do sistema de transporte.

\section{REVISÃO DE LITERATURA}

Uma breve leitura acerca do assunto, já nos permite entender a importância que tem o estudo ergonômico sobre as características de um dado local, seja de trabalho, estudo ou quaisquer outras atividades, para então melhor se projetar as ferramentas e o ambiente, de forma mais adequada a sua realização.

Segundo Moraes e Mont'Alvão (1998) a apreciação ergonômica é entendida como etapa exploratória em que o foco de pesquisa é o mapeamento e delimitação de eventuais problemas. Para tanto, fazem-se necessárias intervenções, sempre com o embasamento em algumas metodologias que levem em consideração toda a dinâmica laboral já citada.

Um estudo ergonômico, segundo as autoras, conta com 5 fases: apreciação, diagnose, projetação, detalhamento/implementação e validação. Nesta pesquisa será abordada apenas a primeira fase, a apreciação.

\section{METODOLOGIA}

A ergonomia faz uso de técnicas e métodos para melhor observar o trabalho humano. De acordo com Moraes e Mont'Alvão (1998), o sistema homem-máquina trata o desempenho humano no trabalho como um todo organizado.

Sistema homem - máquina (SHM): O SHM permite compreender 
por meio gráfico, a entrada e saída do sistema alvo analisado, sua meta que deseja ser alcançada, seus requisitos e restrições, e seus possíveis resultados desapropriados, assim como é visto na imagem a seguir:

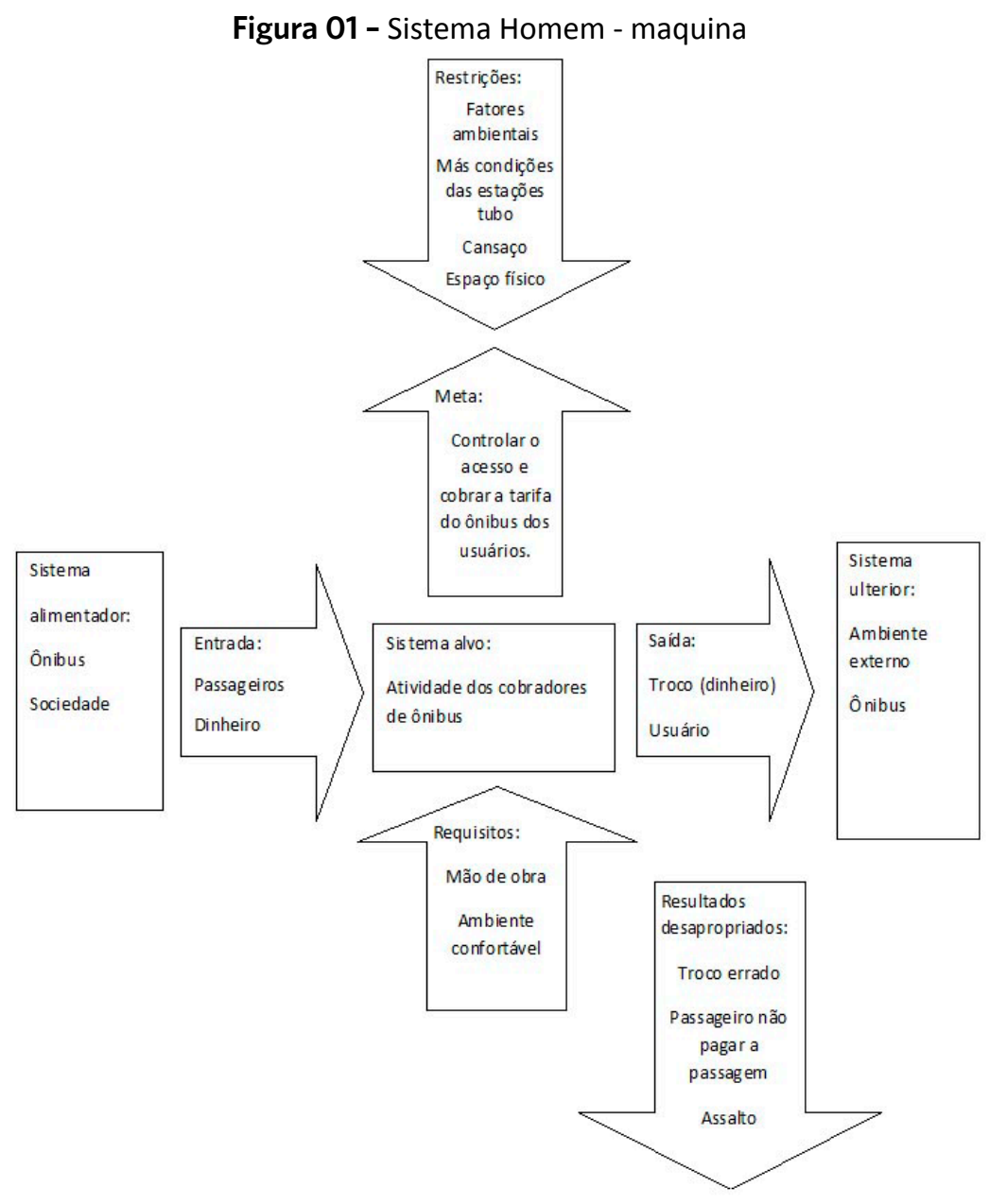

Fonte - Os autores

\section{GUT}

A ferramenta GUT (gravidade, urgência e tendência) segundo Kepner e Tregoe (apud EL MARGHANI, 2011) permite estabelecer uma prioridade entre os fatores analisados, podendo ser adaptada para priorizar algum objetivo.

Por gravidade, compreende-se tudo aquilo que, se deixar de ser atendido, afetará toda a organização do sistema.

Em urgência, temos a consideração do quão necessário é uma dada intervenção em vista do tempo hábil para executar essa intervenção. 
Considera-se tendência, o padrão de desenvolvimento da situação, e sua avaliação está relacionada ao estado que a situação apresentará.

Com base nesses preceitos, tem-se o seguinte resultado:

Tabela 01 - Prioridades de atendimento e correção do sistema - GUT

\begin{tabular}{|c|c|c|c|c|c|}
\hline \multicolumn{2}{|r|}{ Problema } & G & $\mathbf{u}$ & $\mathbf{T}$ & \multirow[b]{2}{*}{18} \\
\hline \multirow[b]{2}{*}{ Postura } & Postura inadequada no local de trabalho & 2 & 3 & 3 & \\
\hline & Assento sem regulagem de distancia & 2 & 2 & 3 & 12 \\
\hline \multirow[b]{3}{*}{ Físico/Ambiental } & Sol & 4 & 3 & 4 & 48 \\
\hline & Chuva & 2 & 2 & 3 & 16 \\
\hline & Vento/frio & 3 & 4 & 3 & 36 \\
\hline \multirow[b]{2}{*}{ Espacial } & Ambiente apertado & 3 & 4 & 4 & 48 \\
\hline & Insegurança & 5 & 5 & 4 & 00 \\
\hline \multirow[b]{2}{*}{ Comunicacional } & Barulho intenso de trânsito & 4 & 3 & 3 & \multirow[t]{2}{*}{36} \\
\hline & & & & & \\
\hline \multirow[t]{3}{*}{ Operacional } & Fluxo intenso de pessoas, stress & 3 & 3 & 4 & \multirow{4}{*}{$\begin{array}{r}36 \\
12 \\
18\end{array}$} \\
\hline & Falta de exercício & 2 & 2 & 3 & \\
\hline & Cansaço muscular & 2 & 3 & 3 & \\
\hline Movimentacional & Lesão por esforco repetitivo & 3 & 3 & 4 & \\
\hline
\end{tabular}

Fonte - Os autores, 2012.

Nota-se que o maior problema se encontra na segurança. Em seguida, os problemas estão relacionados ao bem estar e a saúde do empregado, no caso da continuidade dos problemas apresentados, haverá custos com possível tratamento de saúde do funcionário por conta do mesmo não estar devidamente protegido das intempéries.

\section{ANÁLISE DO AMBIENTE}

O ambiente escolhido foi uma das estações-tubo do círculo militar. Trata-se de uma localização central onde o fluxo' é intenso e constante, e seu funcionamento vai das 6:00 as 24:00, com três escalas de serviço². A escala de serviço de um cobrador de transporte público é da ordem de $5 \times 1$ - cinco dias trabalhados para um de descanço- em um turno de seis horas, eventualmente prolongado por mais três horas, contando como hora extra.

1 Segundo Milton Santos, o espaço é o "conjunto indissociável de sistemas de objetos e sistemas de ações" -fixos e fluxos- que só toma sentido quando se estabelece uma relação de uso desse espaço.

Assim, fluxos, são todos os tipos de relações sociais que ocorrem num dado espaço. 2

Três escalas de seis horas cada, sem intervalos. 
Figura 02 - Fluxograma representativo das atividades diárias do cobrador de ônibus.

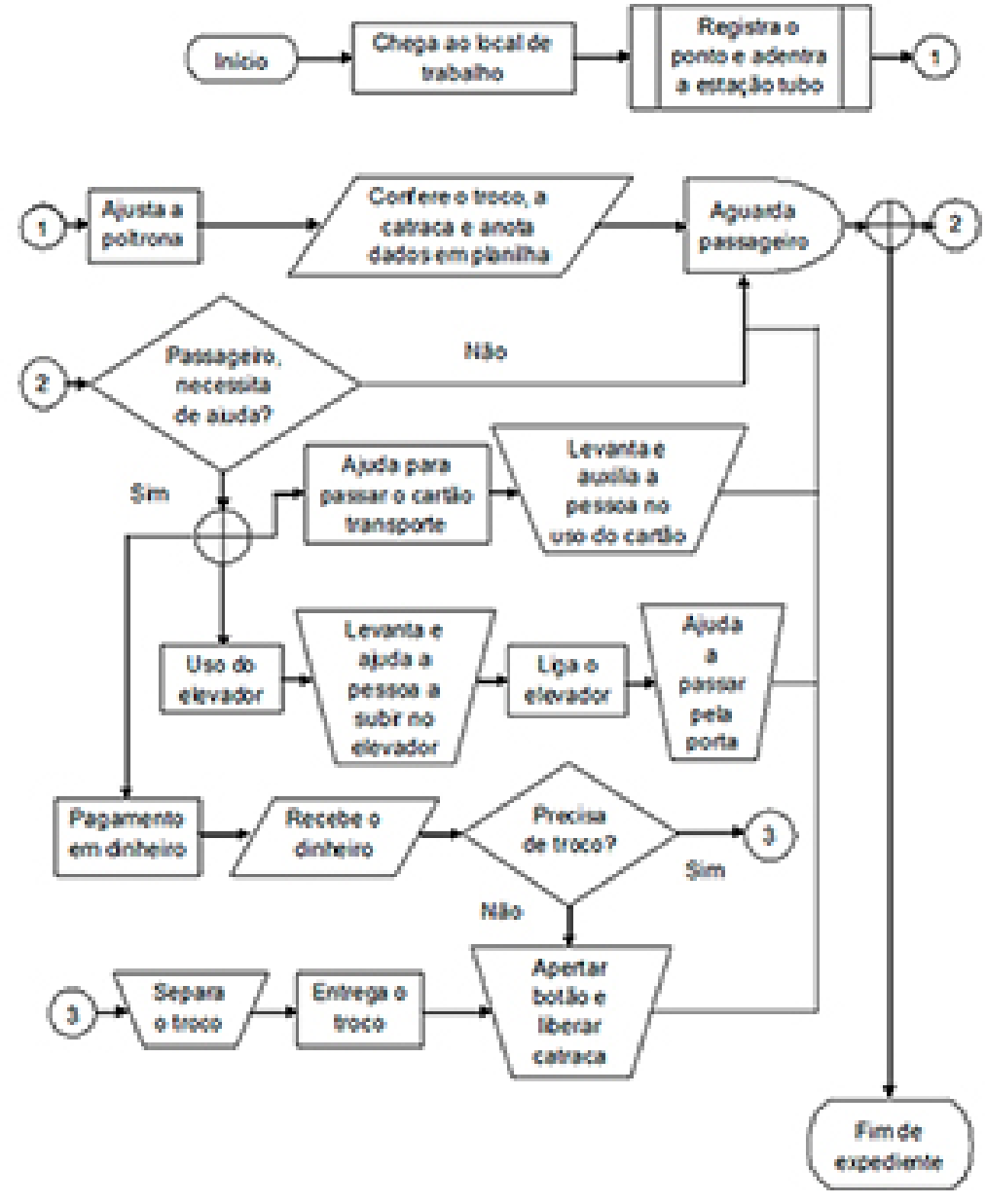

Fonte - Os autores

A estação-tubo é um mobiliário urbano do transporte público de Curitiba, sendo sua manutenção responsabilidade da Urbanização de Curitiba S.A. (URBS). O assento do cobrador é de responsabilidade das empresas de transporte que operam naquela área.

\section{FÍSICO /AMBIENTAL}

A área envidraçada das estações tubo da URBS são revestidas com insulfilm para proteção dos cobradores contra os raios solares. Entretanto, é insuficiente, e nem a URBS, nem a empresa de ônibus, fornece algum outro tipo de EPI, como bonés, e filtro de proteção solar.

Para uma melhor proteção contra o sol, os próprios cobradores compram cortina, para carregarem consigo e utilizarem na estação em que estiverem 
realizando sua escala. Os mesmos também têm a autorização para a utilização de boné, desde que seja de cores neutras.

A estação tubo tem várias vulnerabilidades em sua conformação: o "para vento" - de vidro - instalado ao lado do assento do cobrador, para protegê-lo do vento e da chuva, tem uma fresta (Figura 03), a qual é preenchida com espuma pelos próprios cobradores.

Figura 03- Fresta preenchida com espuma de colchão, pelos próprios cobradores.

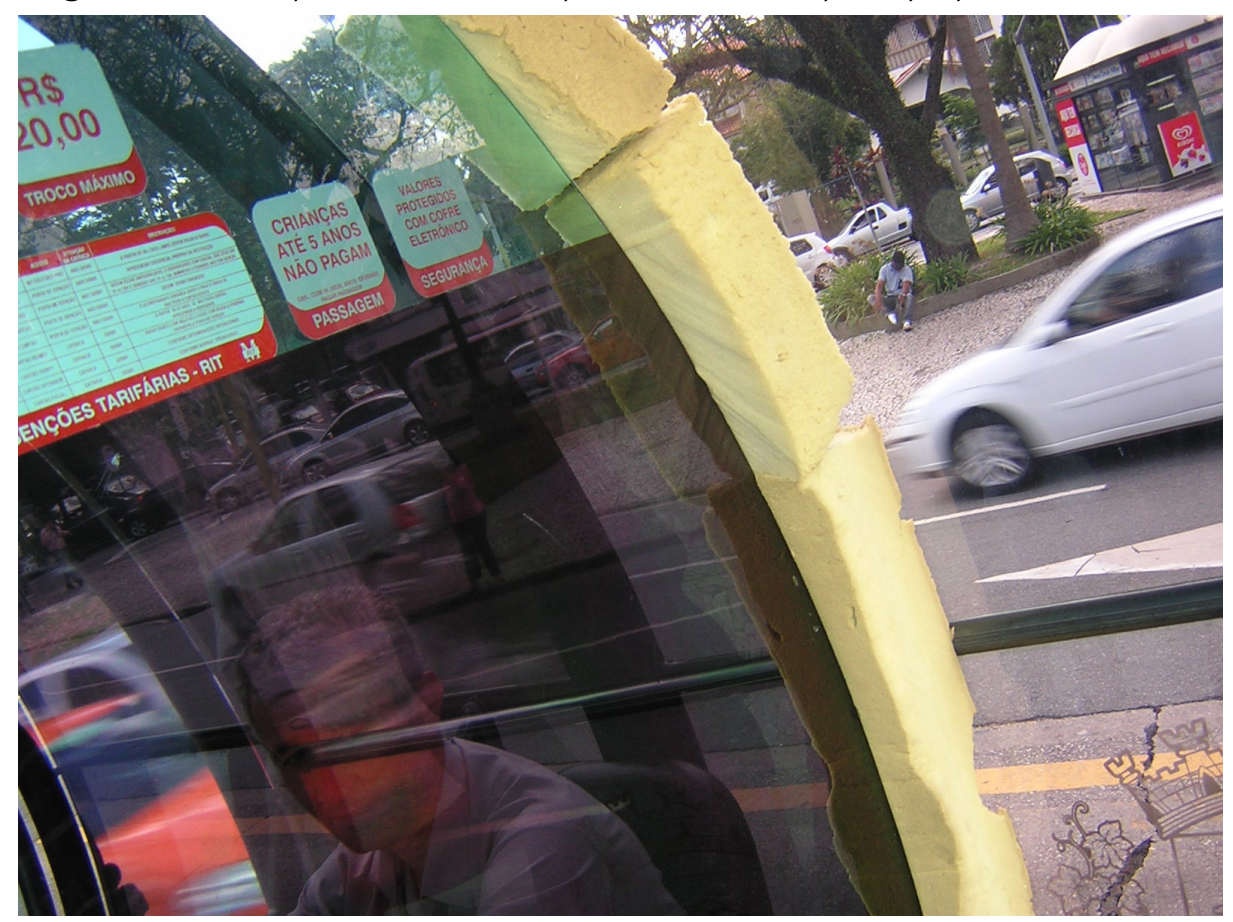

Fonte - Os autores

Chegou a ser divulgado pela imprensa (Agência Bem Paraná, 2011) casos de assédio moral, em quecobradoreserammultados portentarem se proteger do frio. No mesmo ano, ocorreram manifestações por parte dos funcionários do transporte público, e dentre várias solicitações, foi prometido por parte da URBS um reforço no uniforme de inverno dos cobradores das estações-tubo. A categoria aprovou o kit inverno, porém o mesmo não foi entregue até o presente momento. Portanto, qualquer tipo de acessório - manta, jaqueta - continua sendo obtido pelos próprios cobradores.

A poltrona utilizada nas estações tubo (Figura 04) é de responsabilidade das empresas de transporte, esta é considerada confortável, e possui regulagem de altura, mas segundo os cobradores, é impossível permanecer as seis horas da escala de serviço sentado. Portanto, os mesmos afirmam que saem da poltrona para esticar as pernas, sair do calor do sol, no verão - buscar o calor do sol, no inverno - conversar com o colega de trabalho da estação tubo próxima. 
Figura 04 - Poltronas apenas com regulagem de altura

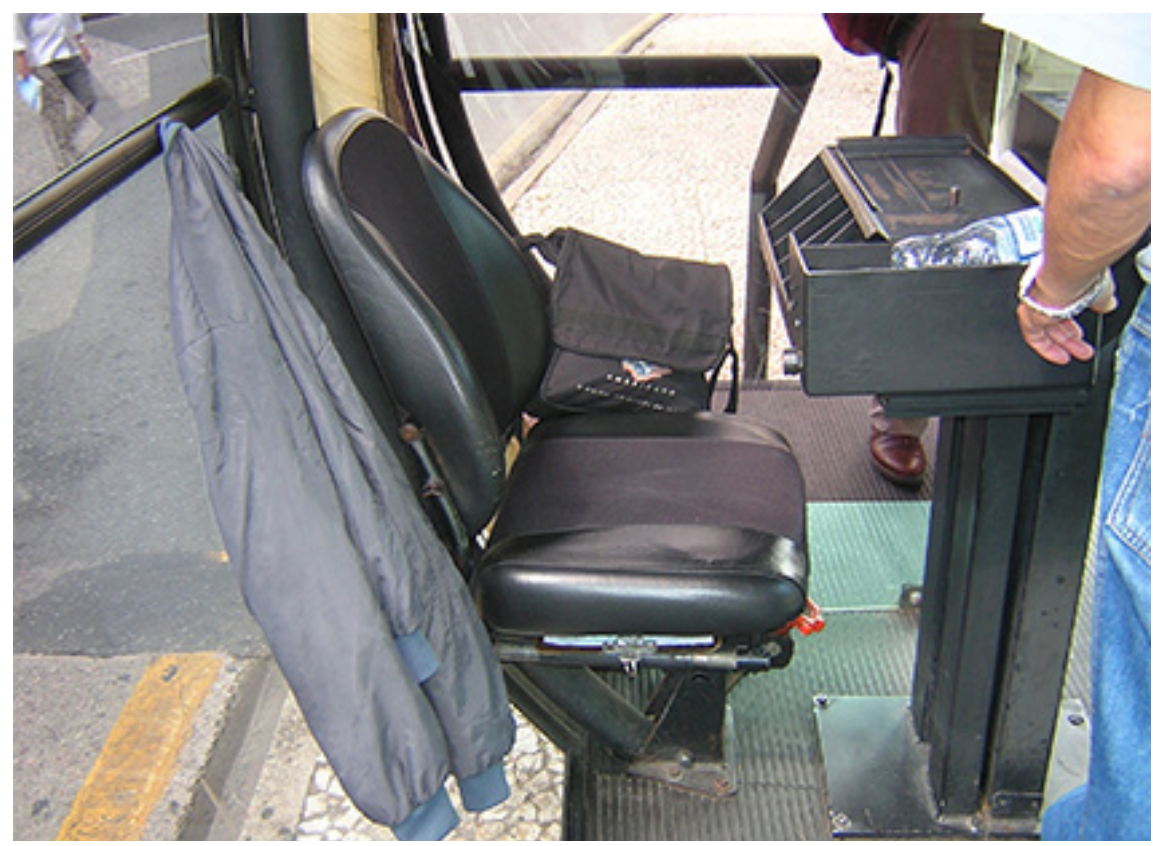

Fonte - Os autores

Outra falha da estrutura estação-tubo é em relação à chuva. Seus "cantos" não têm nenhum sistema de vedação que evite a entrada de água quando chove mais forte. Além disso, a deteriorização da estrutura metálica acaba por ocasionar goteiras no interior das estações (Figura 05).

Figura 05 - O ressecamento da borracha ou a oxidação do ferro permitem a formação de goteiras

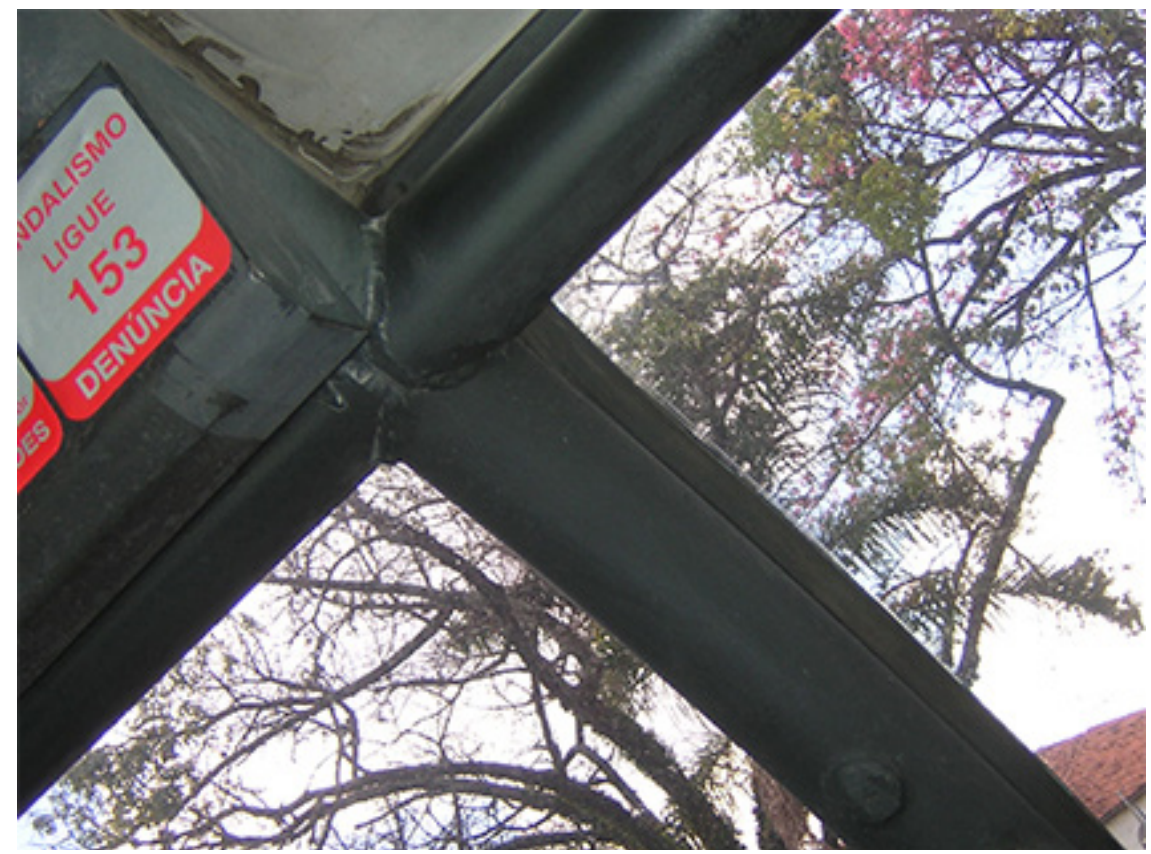

Fonte - Os autores 


\section{ESPACIAL/ INTERIOR}

A estação-tubo de Curitiba foi desenvolvida em 1991, e é considerada um produto inovador. Entretanto, é um ambiente que se torna apertado quando a demanda pelo transporte é alta - horário de pico - não existindo então uma circulação de ar adequada ${ }^{3}$, bem como pouco espaço para locomoção devido ao tamanho da mesma.

\section{COMUNICACIONAL}

Conforme citado anteriormente, o cobrador de ônibus considera "impossível" permanecer sentado por seis horas seguidas. No caso da distância entre as estações de uma linha - ida e volta - impedir que haja comunicação entre os cobradores de tubos diferentes, os cobradores só conversam esporadicamente com usuários do transporte. Existem telefones públicos no interior de alguns tubos, o que, a princípio, de nada adiantaria em um possível assalto.

\section{OPERACIONAL}

Nos horários de pico, o ritmo de trabalho é intenso, havendo uma subjetiva pressão emocional/estresse pelo grande fluxo de pessoas e dinheiro no caixa/ cofre.

\section{AC̣ÃO/MOVIMENTACIONAL/DESLOCAMENTO}

No momento de mexer no caixa/cofre pode haver certo desconforto nesta ação, uma vez que não é possível o ajuste da distancia poltrona-caixa. Um funcionário mais alto ou de maior porte físico, pode sofrer com um ambiente laboral extremamente apertado.

A entrada da estação-tubo é realizada, externamente, pela catraca e/ ou elevador para deficientes, os quais passam por uma pequena porta anexa a catraca. O cobrador é responsável pelo funcionamento do elevador, e pelo 3 Segundo a URBS, foram instalados exaustores nos tubos para melhorar a circulação de ar. Entretanto, esses equipamentos são encontrados em apenas alguns pontos de maior demanda, como a "Estação Praça Eufrásio Corrêa" ou a "Estação Central". 
acesso à estação pela porta de entrada.

Figura 06 - As "pontas" do tubo não são fechadas, ficando usuários e cobrador expostos às intempéries. Elevador para deficientes e porta de vidro anexa à catraca.

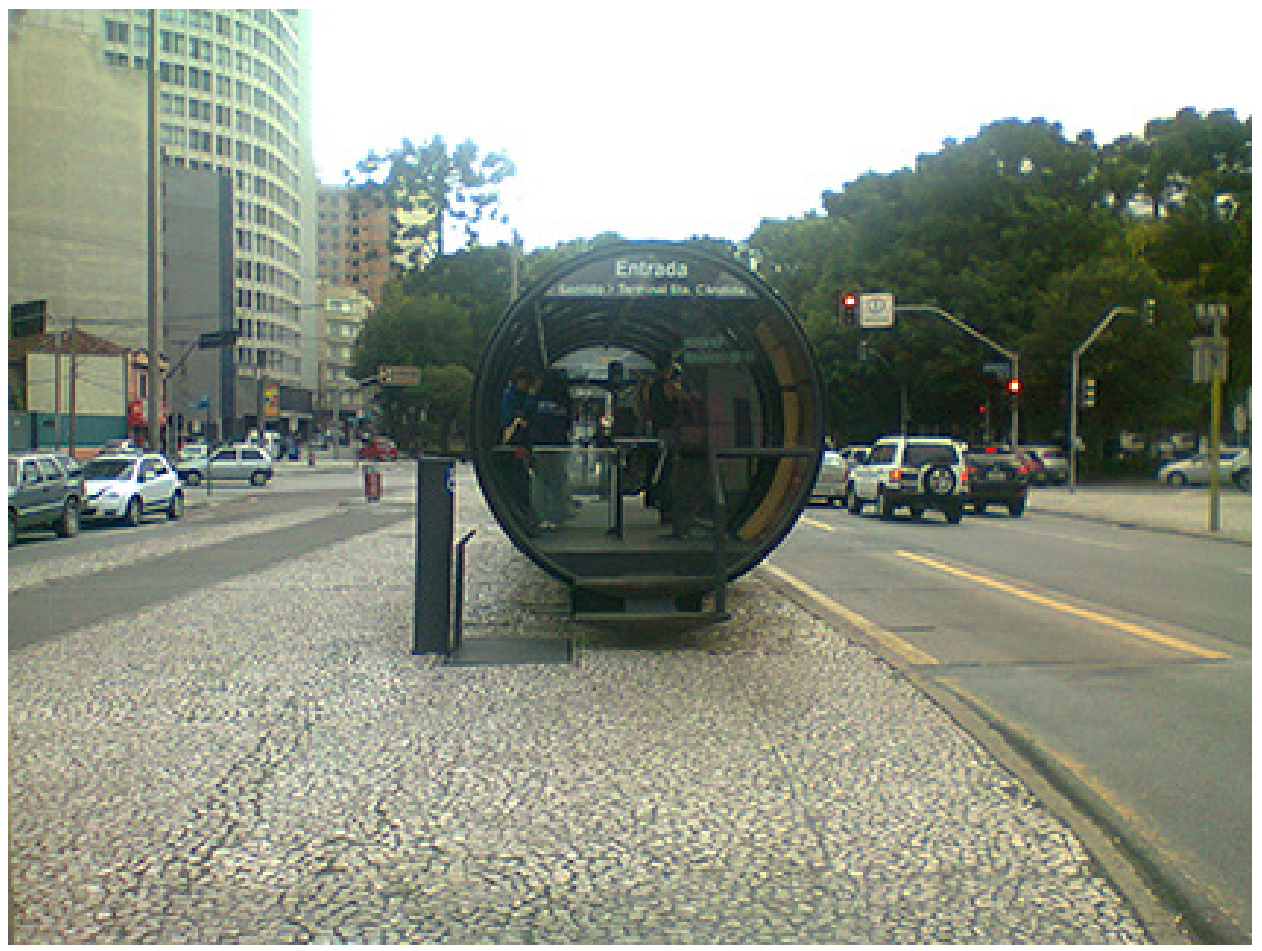

Fonte - Os autores

\section{CONCLUSÃO}

A descrição e análise realizada, através de observações, entrevistas e registros fotográficos, da estação-tubo, permitiu a identificação de algumas falhas ergonômicas. Nota-se que a maioria das tarefas desenvolvidas está relacionada ao atendimento ao público, ficando o tempo que sobra, ocioso, não existindo uma rotina rigorosa, mas semelhante. Em alguns horários, como o de abertura e fechamento do comércio, a movimentação é muito maior, podendo causar relativo estresse, por se tratar de um trabalho diretamente ligado ao atendimento ao público. Portanto, estes postos de trabalho devem ser readequados aos funcionários, a fim de diminuir os problemas diagnosticados. 


\section{REFEERENCIAS}

KAMPA, E.; IWAMOTO, T.; VIDINICH, R. L. Apreciação ergonômica em ambiente de atendimento público: tabelionato no centro de Curitiba. Curitiba: UFPr, 2011.

EL MARGHANI, V. G. R. Fases de apreciação: técnica de GUT. Curitiba: UFPr, 2011.

MORAES, Anamaria; MONT`ALVAO, Claudia. Ergonomia: conceitos e aplicações. Rio de Janeiro: 2AB, 1998.

Redação Bem Paraná. Motoristas e cobradores entregam reivindicações ao presidente da Urbs. Bem Paraná. Disponível em: <

www.bemparana.com.br/noticia/189625/motoristas-e-cobradoresentregam-reivindicacoes-ao-presidente-da-urbs>. Acesso em: 03 abr 2012.

SANTOS, M. A natureza do espaço: tempo e técnica, razão e emoção. São Paulo: Hucitec, 1996.

Rcebeido em: 19/03/2013.

Aceito em: 24/04/2013 